\title{
Functionalization of Cinnamaldehyde to Arylidene barbituric acid, Catalyzed by Samarium(III) Chloride
}

\author{
ANTONIUS HERRY CAHYANA*, BAYU ARDIANSAH and AISYAH NADILA \\ Department of Chemistry, FMIPA, Universitas Indonesia, Depok, 16424 Indonesia. \\ *Corresponding author E-mail: herrykim@ui.ac.id \\ http://dx.doi.org/10.13005/ojc/340565
}

(Received: August 16, 2018; Accepted: August 22, 2018)

\begin{abstract}
Benzaldehyde and cinnamaldehyde were successfully condensed with barbituric acid using samarium(III) chloride in water for $2 \mathrm{~h}$ at room temperature. The products were confirmed through FTIR, UV-Vis and GC-MS analysis.
\end{abstract}

Keywords: Arylidene barbituric acid, Cinnamaldehyde, Functionalization, Samarium(III) chloride, Condensation.

\section{INTRODUCTION}

Cinnamaldehyde $\left(\mathrm{C}_{9} \mathrm{H}_{8} \mathrm{O}\right)$ is an aryl aldehyde and appears as yellow oily liquid ${ }^{1}$. Naturally, it is the main constituent $(60-65 \%)$ of leaf and bark extract of cinnamon, particularly in Indonesian (Cinnamomum burmannii) and Indian (Cinnamomum zeylanicum) cinnamon ${ }^{2,3}$. This compound provides wide range of biological action, like anticancer ${ }^{4}$, anti-inflammatory ${ }^{5}$, antibacterial ${ }^{6}$ and antifungal ${ }^{7}$ properties. Effort to modify cinnamaldehyde into more useful products with attractive bioactivities has been shown in the last decade ${ }^{8-10}$. The presence of $\alpha, \beta$ unsaturated carbonyl group makes cinnamaldehyde as prominent precursor for synthesis of organic molecules with high complexity via various types of organic transformation ${ }^{8-11}$.

One of the key reactions which can be used to modify aryl aldehydes is Knoevenagel condensation. It is valuable reaction to form new $\mathrm{C}-\mathrm{C}$ bond in the production of larger fine chemicals ${ }^{12}$. This reaction involves the abstraction of proton from active methylene compound to give enolate ion then undergo nucleophilic attack to carbonyl group $^{12}$. In 2006, Li et al., synthesized 5-arylidenes barbituric acid via Knoevenagel condensation using grinding method ${ }^{13}$. Various yields of desirable product were found from $35-96 \%$ with 1 to $15 \mathrm{~min}$. grinding time and $120 \mathrm{~min}$. laying time ${ }^{13}$. Khurana and $\mathrm{Vij}$ (2010) performed Knoevenagel condensation of aromatic aldehydes with barbituric acids and 2-thiobarbituric acids using nickel nanoparticles with medium to good yield of isolated products ${ }^{14}$. Other investigation in Knoevenagel condensation using both of homogeneous and heterogeneous catalysts were found in the literature, but some of them were accompanied with limitations, such as in catalyst

This is an Open Access article licensed under a Creative Commons Attribution-Non Commercial-Share Alike 4.0 International License (https://creativecommons.org/licenses/by-nc-sa/4.0/), which permits unrestricted Non Commercial use, distribution and reproduction in any medium, provided the original work is properly cited. 
preparation or the use of harmful solvent , $^{8,12-15}$. Therefore, the search for efficient method or catalyst for Knoevenagel condensation is still become a major challenge.<smiles>[R]C=O</smiles>

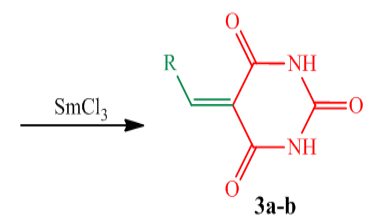

3a: $\mathrm{R}=\mathrm{Ph}-$

3b: $\mathrm{R}=\mathrm{Ph}-\mathrm{CH}=\mathrm{CH}-$

Fig. 1. Reaction scheme of arylidenes barbituric acid synthesis

In this research, we synthesize the arylidene derivatives of barbituric acid using samarium (III) catalyst and characterize the products using some analytical instruments such as FTIR, UV-Vis, and GCMS.

\section{MATERIALS AND METHODS}

\section{General}

All chemicals were analytical grade and obtained from commercial suppliers. FTIR spectra were recorded on Shimadzu Prestige-21 FTIR Spectrophotometer. Ultraviolet-visible absorptions were screened using Shimadzu 2450 UV-Vis Spectrophotometer. GC-MS analyses were done by Agilent 7890A-5975C.

\section{Synthesis of Arylidenes Barbituric Acid}

Aldehyde (1 $\mathrm{mmol})$, barbituric acid (2 mmol), samarium(III) chloride (10 wt.\%) in water $(2 \mathrm{~mL})$ were stirred for $2 \mathrm{~h}$ at room temperature in an Erlenmeyer flask. The reaction was monitored using thin layer chromatography. The product formed will precipitate. After completion, solid product was filtered and recrystallized from hot ethanol.

Compound 3a, 5-benzylidenepyrimidine$2,4,6(1 \mathrm{H}, 3 \mathrm{H}, 5 \mathrm{H})$-trione has physical and spectral data as follows: pale yellow solid, m.p. $261-262^{\circ} \mathrm{C}$ (lit. $271^{\circ} \mathrm{C}$ [18]); $61 \%$ yield; $R_{f} 0.75$ (ethyl acetate : ethanol 7:3) IR (KBr, cm-1): $3629(\mathrm{~N}-\mathrm{H}), 3025(\mathrm{C}-\mathrm{H}$ $\mathrm{sp}^{2}$ ), 1693 (C=O), 1386 (C-N), 697 (mono-substituted benzene). UV-Vis (nm): 230, 258. GC (min.): 13.51. MS (m/z): $216\left(M^{+}\right), 215,172,129,102$.

Compound 3b, (E)-5-(3-phenylallylidene) pyrimidine-2,4,6(1H,3H,5H)-trione has physical and spectral data as follows: yellow solid, m.p. $260-261^{\circ} \mathrm{C}$ (lit. $270^{\circ} \mathrm{C}$ [8]); $68 \%$ yield; $\mathrm{R}_{\mathrm{t}} 0.58$ (ethyl acetate : ethanol 7:3) IR (KBr, cm-1): 3629 (N-H), 3088 (C-H sp $), 1701$ (C=O), 1559 ( $\mathrm{C}=\mathrm{C}$ stretch), 1221 (C-N), 669 (monosubstituted benzene). UV-Vis (nm): 372 . GC (min.): 15.61. MS (m/z): $242\left(\mathrm{M}^{+}\right), 171,155,128,127$.

\section{RESULTS AND DISCUSSION}

The FTIR, UV-Vis, and GC-MS spectra of compound $3 \mathrm{a}$ are presented in the Fig. 2 . In FTIR spectrum, the peaks at 3629,3025 , and $1693 \mathrm{~cm}^{-1}$ are corresponding to the secondary $\mathrm{N}-\mathrm{H}$ stretching, $\mathrm{C}-\mathrm{H} \mathrm{sp}^{2}$ stretching, and $\mathrm{C}=\mathrm{O}$ stretching, respectively. Additional peak appeared at 1386 $\mathrm{cm}^{-1}$ due to C-N stretching and peak at $697 \mathrm{~cm}^{-1}$ indicated the compound $3 \mathrm{a}$ as mono-substituted benzene. Compound 3 a has maximum absorption at $258 \mathrm{~nm}$. The structure confirmation was determined by GC-MS. From GC-MS analysis, compound 3a is the most abundant with retention time at $13.51 \mathrm{~min}$. and $\mathrm{M}^{+}$value of 216 .
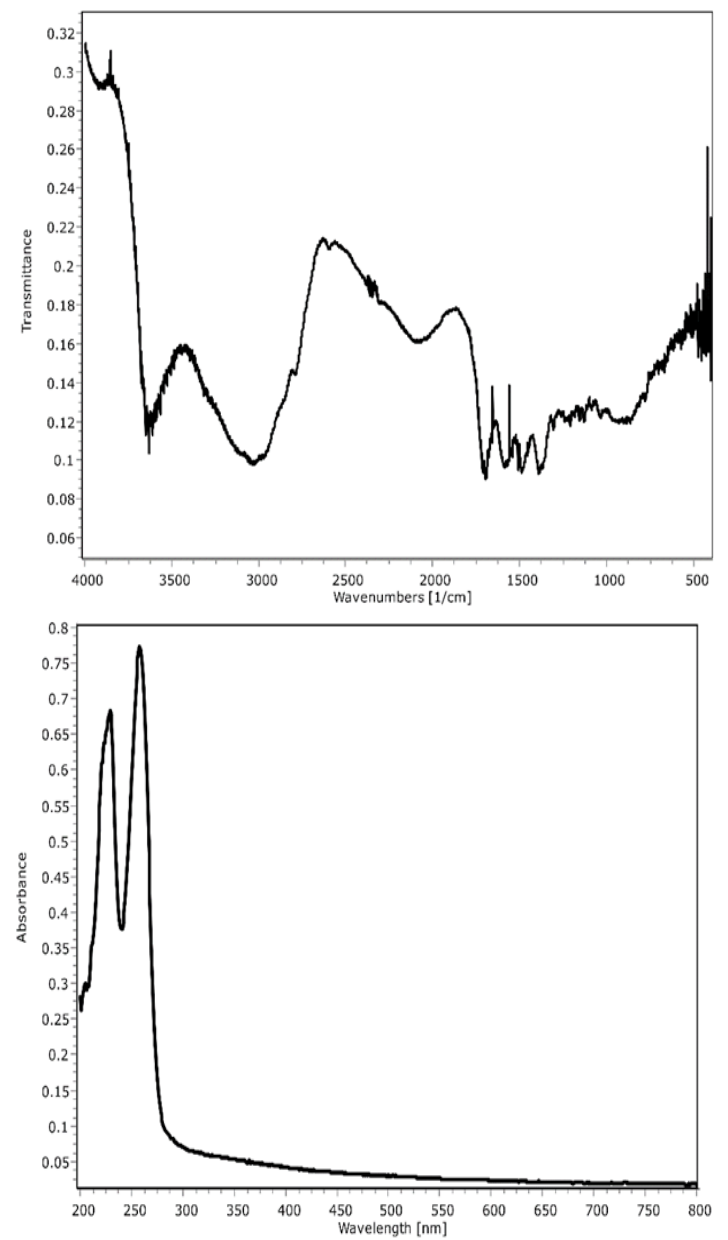

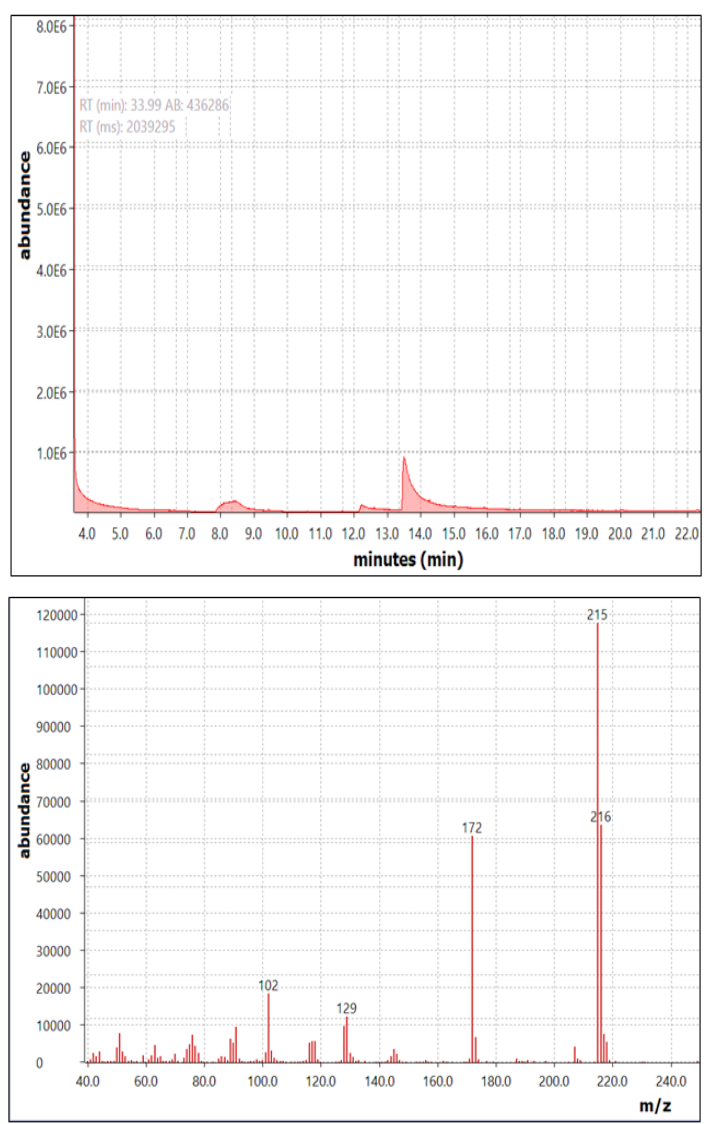

Fig. 2. FTIR, UV-Vis, and GC-MS spectra of compound 3a

Figure 3 showed the FTIR, UV-Vis, and GCMS spectra of compound $3 b$. The major absorption peaks in FTIR spectrum are observed at 3629, 3088, and $1701 \mathrm{~cm}^{-1}$ which attributed to the secondary $\mathrm{N}-\mathrm{H}$ stretching, $\mathrm{C}-\mathrm{H} \mathrm{sp}^{2}$ stretching, and $\mathrm{C}=\mathrm{O}$ stretching vibration, respectively. The peaks at 1559 and 1221 $\mathrm{cm}^{-1}$ are correspond to the $\mathrm{C}=\mathrm{C}$ and $\mathrm{C}-\mathrm{N}$ stretching vibration, respectively. It is indicated the successful adduct between cinnamaldehyde with barbituric acid to give compound $3 \mathrm{~b}$. The maximum absorption of $3 \mathrm{~b}$ is occurred at $372 \mathrm{~nm}$. Analysis using GC-MS revealed that compound $3 \mathrm{~b}$ is formed with molecular cation value of 242. It is in good agreement with our previous work, when the formation of cinnamaldehydebarbituric acid adduct was conducted using citric acid supported on $\mathrm{Fe}_{3} \mathrm{O}_{4}$ as catalys ${ }^{11}$.

The possible mechanism of Knoevenagel condensation between aryl aldehyde and barbituric acid is depicted in Fig. 4. The first step is keto-enol tautomerism of barbituric acid to give structure in enol form. Then a physical interaction occurs between $\mathrm{SmCl}_{3}$ as Lewis acid catalyst with oxygen atom in carbonyl group, which activate the carbon atom. In the second step, the activated carbonyl group is attacked by an enol to produce compound that contains new carbon-carbon bond. The last step is dehydration process to give final product. The product obtained in medium yield probably due to competition between acid base interaction of the catalyst with lone pair electrons in oxygen or nitrogen atom.
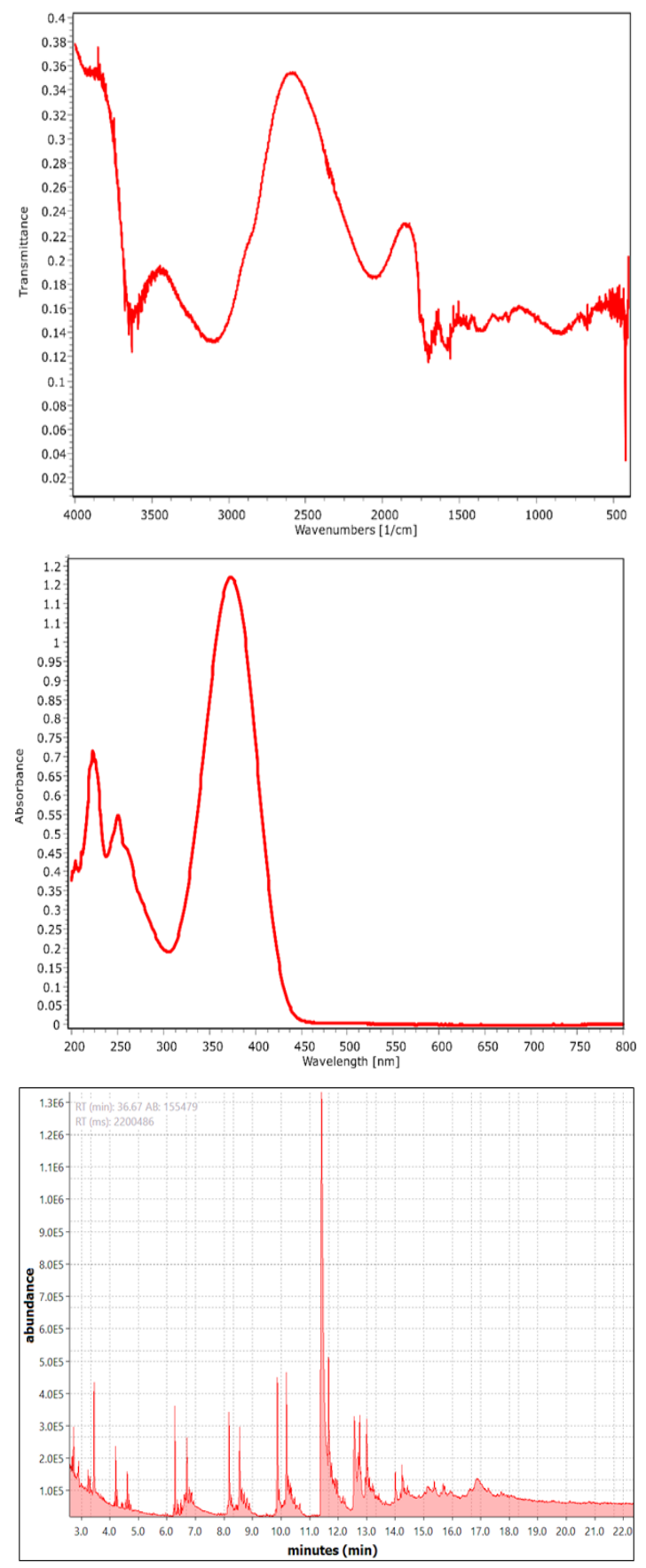


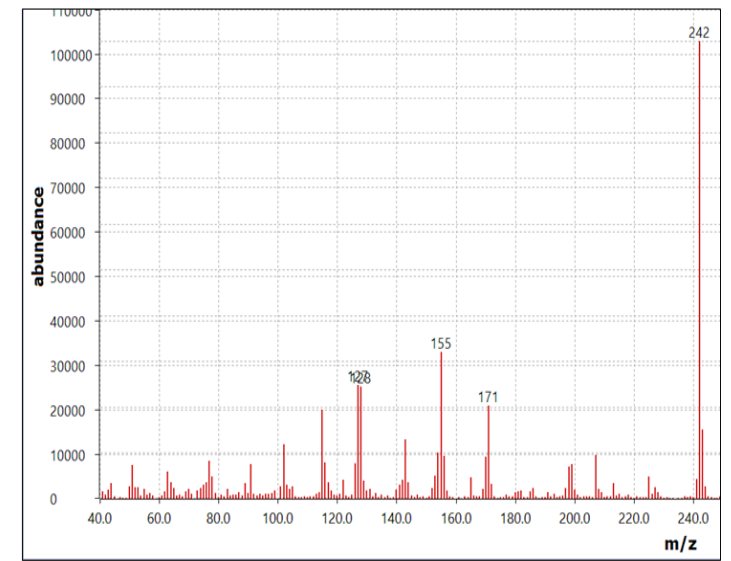

Fig. 3. FTIR, UV-Vis, and GC-MS spectra of compound 3b

\section{CONCLUSION}

The synthesis arylidenes barbituric acid using samarium(III) chloride as Lewis acid catalyst has been done in mild condition. Compound $3 \mathrm{a}$ and $3 \mathrm{~b}$ are formed in medium yield, 61 and $68 \%$, respectively. The successive formation of these compounds was confirmed by some analytical instruments including FTIR, UV-Vis, and GC-MS. This research highlights an environment-friendly

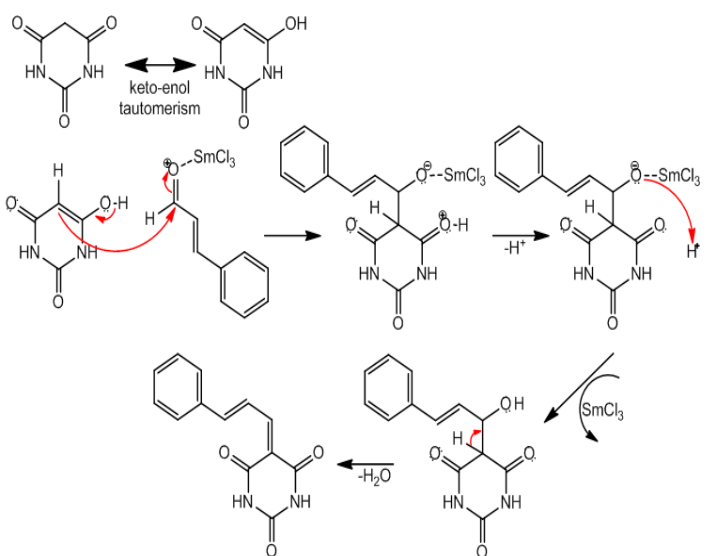

Fig. 4. Proposed mechanism of the condensation reaction

synthesis of organic compound promoted by simple catalyst.

\section{ACKNOWLEDGEMENT}

This work was financially supported by The Directorate General of Higher Education (DIKTI), Ministry of Research, Technology and Higher Education, Republic of Indonesia through Penelitian Unggulan Perguruan Tinggi (PUPT) 2017 Research Grant.

\section{REFERENCES}

1. Shreaz, S.; Wani, W. A.; Behbehani, J. M.; Raja, V.; Irshad, Md.; Karched, M.; Ali, I.; Siddiqi, W. A.; Hun, L. T. Fitoterapia., 2016, 112, 116-131.

2. Wang, R.; Wang, R.; Yang, B. Innov. Food Sci. Emerg. Tech., 2009, 10, 289-292.

3. Lin, L.-T.; Wu, S.-J.; Lin, C.-C. J. Trad. Complement. Med., 2013, 3(4), 227-233.

4. Gan, F. F.; Chua, Y. S.; Scarmagnani, S.; Palaniappan, P.; Franks, M.; Poobalasingam, T.; Bradshaw, T. D.; Westwell, A. D.; Hagen, T. Biochem. Biophys. Res. Commun., 2009, 387, 741-747.

5. Ahn, S.; Kim, E.; Lee, K.; Lee, D.-C. Int. Immunopharmacol., 2016, 38, 342-348.

6. Lee, H. S.; Ahn, Y. J. J. Agric. Food Chem., 1998, 46, 8-12.

7. Aziz, A. N.; Ibrahim, H.; Rosmy Syamsir, D.; Mohtar, M.; Vejayan, J.; Awang, K. J. Etnopharmacol., 2013, 145, 798-802.

8. Rajput, J. K.; Kaur, G. Chinese J. Catal., 2013, 34, 1697-1704.

9. Cahyana, A. H.; Pratiwi, D.; Ardiansah, B. Rasayan J. Chem., 2016, 9(4), 896-902.
10. Cahyana, A. H.; Nadila, A.; Ardiansah, B. AIP Conf. Proc. 2017, 1862, Article ID 030097. DOI: $10.1063 / 1.4991201$.

11. Cahyana, A. H.; Pratiwi, D.; Ardiansah, B. IOP Conf. Ser.: Mater. Sci. Eng., 2017, 188, Article ID 012008. DOI: 10.1088/1757899X/188/1/012008.

12. Tangale, N. P.; Sonar, S. K.; Niphadkar, P. S.; Joshi, P. N. J. Ind. Eng. Chem., 2016, 40, 128-136.

13. Li, J.-T.; Dai, H.-G.; Liu, D.; Li, T.-S. Synth. Commun., 2006, 36, 789-794.

14. Khurana, J. M.; Vij, K. Catal. Lett., 2010, 138, 104-110.

15. Wang, C.; Ma, J.-J.; Zhou, X.; Zang, X.-H.; Wang, Z.; Gao, Y.-J.; Cui, P.-L. Synth. Commun., 2005, 35, 2759-2764.

16. Sakthivel, B.; Dhakshinamoorthy, A. J. Coll. Interf. Sci., 2017, 485, 75-80.

17. Rana, S.; Jonnalagadda, S. B. Catal. Commun., 2017, 92, 31-34.

18. Alcerreca, G.; Sanabria, R.; Miranda, R.; Arroyo, G.; Tamariz, J.; Delgado, F. Synth. Commun., 2000, 30(7), 1295-1301. 